\title{
Brain Drain: Using the Deep Venous System to Declare Brain Death
}

Can. J. Neurol. Sci. 2010; 37: 429-430

The neurological determination of death or brain death is accepted in Canada and many countries as proof of death of the individual. ${ }^{1,2}$ This allows for the mandatory discontinuation of "life support measures" (ventilators, blood pressure control, hormonal supplements and warming techniques) and the transplantation of organs if consent is obtained. The "gold standard" is the clinical assessment and must fulfill the following criteria: the cause must be known and the etiology must be capable of causing neuronal death, the cranial nerve reflexes are absent, there are no brain-originating movements that are either spontaneous or evoked and apnea is assured with a reliable technique. ${ }^{1,3}$ Certain caveats apply: testing must be done after 24 hours in cases of cardiac arrest, the core temperature should be $34^{\circ} \mathrm{C}$ or greater, and there should not be any confounders such as: unresuscitated shock, severe metabolic disorders capable of causing a potentially reversible coma, peripheral nerve or muscle dysfunction or neuromuscular blockade potentially accounting for unresponsiveness or clinically significant drug intoxications (e.g., alcohol, bar-biturates, sedatives or hypnotics). ${ }^{1}$

Ancillary tests are needed when the clinical criteria cannot be applied, e.g., inability to test cranial nerve reflexes, high spinal cord injury or severe peripheral neuropathy, or the presence of sedative drugs for which a quantitative assay is not possible. ${ }^{4}$ (This scenario is not uncommon: Savard and colleagues found that ancillary testing was needed in $23 \%$ of patients suspected of being brain dead..$^{5}$ Such ancillary tests meet the following criteria: 1 . There should be no "false positives", i.e., when the test is positive there should be no patients who have the potential to recover brain function; 2 . The test should be capable of "standing alone" as proof that brain death is present; 3 . The test should be standardized in technology, technique and the classification of results; 4 . The test should be readily available, safe and easily applied in most centres having intensive care units. ${ }^{4}$ Only tests of intracranial blood circulation meet these criteria. ${ }^{4}$ Electrophysiological (EEG and evoked responses) tests, metabolic studies, jugular venous oxygen and the atropine test are not adequate. ${ }^{4}$ Among tests of brain blood flow and circulation, the following techniques are accepted in Canada as valid: 4 vessel (carotids and vertebrals) angiography, radionuclide scanning, CT angiography and MR angiography. ${ }^{6}$ There is a paucity of studies confirming the validity of brain blood flow in patients found to be brain dead clinically. ${ }^{4}$ However, if we accept as axiomatic that a brain without a blood supply is not viable, a priori if the test can reliably show that the brain at normal temperature is not being perfused for a sufficient period of time this should suffice.

A reliable test of brain perfusion is the ideal objective here. The angiographic studies mentioned above assess tests of intracranial blood circulation, which is are not necessarily equivalent to brain tissue perfusion. If there is no blood getting into the intracranial compartment whatsoever, there cannot be brain perfusion. However, there can be "false negatives" if we insist on the absence of proximal intracranial artery filling by angiographic techniques. This can occur without the brain parenchyma being perfused and is more likely to happen when there is decompression of the intracranial compartment by a traumatic or neurosurgical skull breach. (It should also be noted that filling of the superior sagittal sinus through diploic venous feeders can occur in brain death and this is commonly allowed.) Tests that demonstrate perfusion of brain tissue include: 1 . Computed tomogram perfusion studies ${ }^{7}$ (complex and not widely utilized or available); 2. Radionuclide studies such as single photon emission computed tomography scanning with Tc99-labelled hexamethylpropylamineoxime or ethyl cysteinate dimer, agents that pass from blood into brain on their first pass through the tissue ${ }^{8} ; 3$. magnetic resonance perfusion techniques; ${ }^{9-12} 4$. filling of deep cerebral veins (these drain brain tissue only, unlike the superior sagittal sinus). The latter does not require special technology and should be as available as angiography.

Cerebral perfusion, when absent, is an acceptable proof of brain death, but this is not ideal. In cases of brain death where intracranial pressure does not exceed mean arterial pressure, there may be a total absence of function despite the presence of perfusion. ${ }^{12,13}$ Such cases are more likely to occur when the ancillary test is performed early in the course of brain death, before the intracranial pressure rises sufficiently to prevent intracranial circulation, or in patients for whom the cause of brain death is one that is not associated with increased intracranial pressure. For such cases, which will undoubtedly be few in number, a test of cerebral function is necessary to avoid false negatives.

Savard and colleagues reviewed the records of 34 patients who required ancillary testing for brain death and showed absent deep venous filling. ${ }^{5}$ Nine of these had some proximal intracranial arterial opacification. Thus $28 \%$ would have been "false negatives" for brain death declaration. This could translate into a sizable number of patients who could not serve as organ donors as they could not be declared brain dead by standard 4 vessel angiography. Although their study involves a small number of patients with a high incidence of skull defects, is retrospective and without other confirmation, they make a valuable point. We need to concentrate more on tests of brain perfusion as the better method for declaring brain death in those who require ancillary testing. This should be a priority initiative for improving brain death declaration.

G. Bryan Young, London, Ontario, Canada Jeanne Teitelbaum, Montreal, Quebec, Canada 


\section{REFERENCES}

1. Shemie SD, Doig C, Dickens D, et al. Brain arrest: the neurological determination of death and organ donor management in Canada. Severe brain injury to neurological determination of the death. Canadian forum recommendations. CMAJ. 2006;174:S1-13.

2. Wijdicks EG. Brain death worldwide. Accepted fact but no global consensus on criteria. Neurology. 2006;58:20-5.

3. Saposnik G, Basile VS, Young GB. Movements in brain death: a systematic review. Can J Neurol Sci. 2009;36:154-60.

4. Young GB, Shemie SD, Doig CJ, Teitelbaum J. Brief review: the role of ancillary tests in the neurological determination of death. Can J Anaesth. 2006;53:620-7.

5. Savard M, Turgeon AF, Gariepy J-L, Trottier F, Langevin S. Selective 4 vessel angiography in brain death: a retrospective study. Can J Neurol Sci. 2010;37:492-7.

6. Shemie SD, Lee D, Sharpe M, Tampieri, Young B. Brain blood flow in the neurological determination of death: Canadian expert report. Can J Neurol Sci. 2008;35:140-6.
7. Roberts HC, Roberts TP, Smith WS, et al. Multisection dynamic CT perfusion for acute cerebral ischemia: the "toggling-table" technique. AJNR Am J Neuroradiol. 2001;22:1077-80.

8. Spieth ME, Ansari AN, Kawada TK, Kimura RL, Siegel ME. Direct comparison of Tc-99m DPTA and Tc-99 HMPAO for evaluating brain death. Clin Nucl Med. 1994;19:867-72.

9. Barbier EL, Lamalle L, Decorps M. Methodology of brain perfusion imaging. J Magn Reson Imaging. 2001;13(4):496-520.

10. Wu O, Ostergaard L, Sorenson AG. Technical aspects of perfusionweighted imaging. Neuroimaging Clin N Am. 2005;15(3): 623-37.

11. Duyn JH, van Gelderen P, Talagala L, Koretsky A, de Zwart JA. Technological advances in MRI measurement of brain perfusion. J Magn Reson Imaging. 2005;22:751-3.

12. Ala TA, Kuhn MJ, Johnson HJ. A case meeting clinical brain death criteria with residual cerebral perfusion. AJNR. 2006;27:805-6.

13. Wijdicks EFM. Brain death. Philadelphia: Williams and Wilkins; 2001. p. $78-80$ 